\title{
Ethnic differences in dissatisfaction with sexual life in patients with type 2 diabetes in a Swedish town
}

\author{
Marina Taloyan ${ }^{1 *}$, Alexandre Wajngot ${ }^{2}$, Sven-Erik Johansson ${ }^{1,2}$, Jonas Tovi ${ }^{2}$ Jan Sundquist ${ }^{1,3}$
}

\begin{abstract}
Background: The first aim of this study was to analyze whether self-reported satisfaction with one's sexual life was associated with ethnicity (Swedish and Assyrian/Syrian) in patients with type 2 diabetes. The second was to study whether the association between satisfaction with one's sexual life and ethnicity remained after controlling for possible confounders such as marital status, $\mathrm{HbA1c}$, medication, and presence of other diseases.

Methods: This cross-sectional, questionnaire-based study was conducted at four primary health care centers in the Swedish town of Södertälje. A total of 354 persons (173 ethnic Assyrians/Syrians and 181 ethnic Swedes) participated.

Results: The total prevalence of self-reported dissatisfaction with one's sexual life in both groups was $49 \%$. No significant ethnic differences were found in the outcome. In the final model, regardless of ethnicity, the odds ratio (OR) for self-reported dissatisfaction with one's sexual life in those $\geq 70$ years old was 2.52 (95\% Cl 1.33-4.80). Among those living alone or with children, the OR was more than three times higher than for married or cohabiting individuals $(\mathrm{OR}=3.10,95 \% \mathrm{Cl} 1.60-6.00)$. Those with other diseases had an OR 1.89 times $(95 \% \mathrm{Cl} 1.10$ 3.40) higher than those without other diseases.

Conclusions: The findings demonstrate that almost half of participants were dissatisfied with their sexual life and highlight the importance of sexual life to people with type 2 diabetes. This factor should not be ignored in clinical evaluations. Moreover, the findings demonstrate that it is possible to include questions on sexual life in investigations of patients with type 2 diabetes and even in other health-related, questionnaire studies, despite the sensitivity of the issue of sexuality.
\end{abstract}

\section{Background}

Sexual problems are common complications of diabetic disease in both men and women [1-6]. In general, the prevalence of sexual dysfunction increases with age [7-9] and in the presence of cardiovascular disease $[10,11]$. Furthermore, changes in hormones and endocrine function [12], biochemical factors (HbA1c, triglycerides), and psychosocial factors [13-16] can also have an impact on sexual function.

Few studies have investigated sexuality in people from different ethnic groups who have diabetes. An explorative Swedish study by Hjelm et al. concluded that there

\footnotetext{
* Correspondence: marina.taloyan@sll.se

'Center for Primary Health Care Research, Region Skåne, Lund University, Lund, Sweden

Full list of author information is available at the end of the article
}

were different beliefs about health and illness in men with diabetes in different ethnic groups. According to the results of this study, Swedes focused on heredity, lifestyle, and management of diabetes, while sexual function was reported as one of the factors important to health among Arabs and men from the former Yugoslavia [17]. Few studies address female sexuality and sexual expression in immigrant women with diabetes. For cultural reasons and because of methodological difficulties, the association between type 2 diabetes and sexual function in women has been studied in fewer objective studies than the effects of diabetes on sexual function in men [4].

Although we believed that questions regarding sexual life would be sensitive, we included three questions about this matter in the questionnaire used to 
investigate the health and well-being of patients with type 2 diabetes in the town of Södertälje. The aim was to analyze whether self-reported satisfaction with one's sexual life was associated with ethnicity (Swedish and Assyrian/Syrian) in patients with type 2 diabetes and when taking age and biological sex into consideration. We also wanted to study if any such association between satisfaction with one's sexual life and ethnicity remained when possible confounders such as marital status, HbA1c, medication, and other diseases were taken into consideration.

\section{Methods}

\section{Sample}

The participants were selected from the registers of patients with type 2 diabetes at four primary health care centers in the town of Södertälje. A total of 354 individuals were included: ethnic Assyrians/Syrians $(\mathrm{n}=173)$ and ethnic Swedes $(n=181)$. They were matched according to gender and age. Those who identified themselves as neither Assyrian/Syrian nor Swedish were excluded from the study. Ethnicity is discussed further in the section on explanatory variables below.

The patients were contacted by telephone and later filled out a questionnaire at their health care center in the presence of an interviewer (the first author or a GP), who helped with the questions as needed. Interpreters were also used as needed. Medical information and laboratory data from the patient records of all participants were gathered. Verbal informed consent was obtained for participation in the study and for the gathering of data from patient records.

The 61 participants who did not answer the question about the level of satisfaction with their sexual life and the two participants who identified themselves as neither ethnic Assyrians/Syrians nor ethnic Swedes were excluded from the study, leaving a total of 291 participants: 129 Assyrians/Syrians and 162 Swedes.

\section{Outcome variable}

Information on the outcome variable, self-reported dissatisfaction with one's sexual life, was obtained from the answers to one of three questions on sexual life asked as part of the larger structured health questionnaire developed specifically for this study. The outcome of the study is based on the question: "Are you satisfied with your sexual life?" Another two questions (concerning loss of ability to have sexual intercource and loss of sexual desire) are not included in this study. Five answers were possible: "very dissatisfied," "quite dissatisfied," "rather satisfied," "quite satisfied", and "very satisfied". Those who reported that they were "very dissatisfied," "quite dissatisfied," or "rather satisfied" were categorized as having self-reported dissatisfaction with their sexual life.

Before asking the participants the three questions about satisfaction/dissatisfaction with their sexual life, we informed them: "The following questions can be perceived as sensitive; please answer as well as you can." This information was provided on the questionnaire and verbally, as necessary, for clarification. Verbally, the interviewers also explained that the reason we were asking these questions was that type 2 diabetes can have complications that may affect one's sexual life.

\section{Explanatory variables}

The variable Self-reported ethnicity included two groups: Assyrians/Syrians and Swedes. Assyrians/Syrians are an ancient ethnic group from Mesopotamia whose Christian religion is an important part of their identity [18]. There are approximately 70,000 to 80,000 Assyrians/Syrians in Sweden [18], originating mainly from Turkey, Syria, Iraq, and Lebanon. About 20,000 Assyrians/Syrians live in Södertälje.

Assyrians belong to one of four churches: the SyrianOrthodox, the Nestorian, the Chaldeian, and the SyrianCatholic. Individuals from the Syrian-Orthodox group and those who do not want to be defined as Assyrian may identify themselves as Syrian [19]. Thus, both terms were used in the questionnaire.

Official Swedish statistics do not include information on ethnicity; rather, persons are identified by country of birth, parents' country of birth, and citizenship. For this reason, the identification of potential participants by ethnicity took place in two stages. To begin with, the first author and personnel from the primary health care centers in Södertälje examined the list of patients with diabetes from each of the four participating primary health care centers. Using participants' surnames and the health care center personnel's personal knowledge of patients, the first author and the health care center personnel identified persons they believed to be ethnic Assyrians/Syrians or Swedes. The first author then developed a sex- and age-matched list of prospective Assyrian/Syrian and Swedish responders. Health care center personnel contacted prospective responders by phone and invited them to fill out the questionnaire at the primary health care center.

One of the questions on the questionnaire was about ethnicity. The Assyrian/Syrian participants all came from Middle Eastern countries: 33.5\% from Turkey, $30.6 \%$ from Iraq, $20.2 \%$ from Syria, and the remainder from Lebanon and other countries.

Age was divided into three groups: 32-59, 60-69 and $\geq$ 70 years, to obtain similar proportions of patients in each group. 
Marital status was divided into two groups. The first consisted of those who were married or cohabiting, and the second consisted of both those who lived without a wife/husband, whether living alone or with their children, because of the small sample size of participants in the latter group.

$H b A 1 c$ was divided into two groups: normal $(\leq 6.0 \%)$ and high $(<6.0 \%)$. HbA1c was measured using the Swedish mono-S method [20].

Medication was based on the question "Do you take blood sugar reducing medicine and/or insulin? There were two response alternatives "yes. Which?" and "no". Positive responses were considered as having medication (drugs and/or insulin) and all negative answers were classified as not having medication.

Other disease(s) was defined on the basis of the question, "Do you have other diseases? (Yes/No)". All "yes" answers were categorized as having other disease(s) and all "no" answers were categorized as not having other disease(s).

\section{Statistical analyses}

Pearson's chi-2 test and the t-test were used to calculate whether differences between the two ethnic groups in the prevalence of sociodemographic characteristics were statistically significant. Prevalence of the outcome variable was calculated in the same way. Unconditional logistic regression was used to calculate the odds ratios (ORs) and 95\% confidence intervals (95\% CIs) to investigate the relation between self-reported dissatisfaction with one's sexual life and the explanatory variables. All explanatory variables, which included ethnicity, sex, age (years), marital status, HbA1c, medication, and other diseases were introduced stepwise into the models. The fit of the models was judged by the Hosmer-Lemeshow goodness-of-fit test. The models were considered acceptable at $\mathrm{p}>0.05$, and both models met this demand [21]. The statistical software program used was Stata v.9 [22].

\section{Ethical considerations}

The study was approved by the Regional Ethical Committee of Karolinska Institutet (reference number 2006/ 4:8, 2006-09-27).

\section{Results}

The questionnaire/interview was completed by 354 participants. Of these participants, 83\% $(\mathrm{n}=291)$ responded to the question about satisfaction with their sexual life. The response rate was $75 \%$ among the Assyrians/Syrians and $90 \%$ among the Swedes. In total, $94 \%$ of men (62.8\% of Assyrian/Syrian men and $60.5 \%$ of Swedish men) and $68 \%$ of women (37.2\% of Assyrian/ Syrian women and $39.5 \%$ of Swedish women) answered
Table 1 Distribution (\%) of the explanatory variables by ethnicity $(n=291)$

\begin{tabular}{lccc}
\hline Variable & \multicolumn{2}{c}{ Ethnicity } & \\
& Assyrian/ & Swedish & Test of \\
& Syrian & $(\mathrm{n}=$ & difference \\
& $(\mathrm{n}=129)$ & $162)$ & \\
\hline
\end{tabular}

\begin{tabular}{|c|c|c|c|}
\hline \multicolumn{4}{|l|}{ Gender } \\
\hline Female & 37.2 & 39.5 & \\
\hline Male & 62.8 & 60.5 & \\
\hline Age (years) & & & 0.000 \\
\hline $32-59$ & 57.4 & 33.3 & \\
\hline 60-69 & 22.5 & 34.0 & \\
\hline$\geq 70$ & 20.1 & 32.7 & \\
\hline Marital status & & & 0.000 \\
\hline Married/cohabiting & 91.5 & 63.0 & \\
\hline $\begin{array}{l}\text { Living alone/with } \\
\text { children }\end{array}$ & 8.5 & 37.0 & \\
\hline Abnormal HbA1c & 50.0 & 37.2 & 0.030 \\
\hline Medication (yes) & 78.0 & 79.0 & 0.890 \\
\hline Other diseases & 70.8 & 71.4 & 0.918 \\
\hline
\end{tabular}

the question. A comparison of nonresponders in both ethnic groups showed no significant differences with regard to such explanatory variables as marital status.

There were statistically significant differences between the ethnic groups with regard to a number of explanatory variables (Table 1). In comparison to the Swedes, the Assyrians/Syrians were younger, fewer lived alone or with children $(8.5 \%$ vs. $37.0 \%)$, and a significantly higher number had abnormal HbA1c.

The total prevalence of self-reported dissatisfaction with one's sexual life in both groups was 49\% (not shown in table). No significant difference in this selfreported dissatisfaction was noted between the ethnic groups; as shown in Table 2, a total of $46.5 \%$ of the Assyrians/Syrians and $51.0 \%$ of the Swedes reported dissatisfaction. In both ethnic groups, more participants who lived alone or with children were dissatisfied than those who were married or cohabiting, but in the Assyrian/Syrian group, only $8.5 \%$ of the participants lived alone or with children. The responders in the oldest group ( $\geq 70$ years) were the next most dissatisfied group.

Table 3 shows the association between ethnicity and self-reported dissatisfaction with one's sexual life in two models: Model 1, adjusted for age and biological sex, and Model 2, adjusted for age, biological sex, marital status, HbA1c, medication, and presence of other 
Table 2 Prevalence (\%) of self-reported dissatisfaction with one's sexual life by the explanatory variables and ethnicity $(n=291)$

\begin{tabular}{|c|c|c|c|}
\hline \multirow[t]{2}{*}{ Variable } & \multicolumn{2}{|c|}{ Ethnicity } & \multirow[b]{2}{*}{$\begin{array}{c}\text { Test of } \\
\text { difference }\end{array}$} \\
\hline & $\begin{array}{c}\text { Assyrian/ } \\
\text { Syrian } \\
(n=129)\end{array}$ & $\begin{array}{c}\text { Swedish } \\
(\mathrm{n}= \\
162)\end{array}$ & \\
\hline Total & 46.5 & 51.0 & NS \\
\hline Gender & & & NS \\
\hline Female & 54.2 & 45.3 & \\
\hline Male & 42.0 & 54.1 & \\
\hline Age (years) & & & NS \\
\hline $32-59$ & 40.5 & 42.6 & \\
\hline 60-69 & 51.7 & 50.0 & \\
\hline$\geq 70$ & 57.7 & 60.4 & \\
\hline Marital status & & & NS \\
\hline Married/cohabiting & 43.2 & 43.0 & \\
\hline $\begin{array}{l}\text { Living alone/with } \\
\text { children }\end{array}$ & 81.8 & 61.0 & \\
\hline Abnormal HbA1c & & & NS \\
\hline Yes & 51.6 & 48.3 & \\
\hline No & 42.2 & 52.0 & \\
\hline Medication & & & NS \\
\hline Yes & 46.1 & 49.0 & \\
\hline No & 48.0 & 55.2 & \\
\hline Other diseases & & & NS \\
\hline Yes & 49.0 & 57.1 & \\
\hline No & 40.5 & 35.7 & \\
\hline
\end{tabular}

diseases. There were no statistically significant differences between Assyrians/Syrians and Swedes with regard to the outcome variable in Model 1 or 2. No significant differences with regard to the outcome variable were found by biological sex in either model. The ORs for dissatisfaction with one's sexual life in those $\geq 70$ years old was significantly higher $(\mathrm{OR}=2.40,95 \%$, CI 1.24-4.52) than for those in the younger age groups (OR $=1.54,95 \%$ CI 0.83-2.84) in Model 1. In Model 2, the OR increased in those $\geq 70$ years old $(\mathrm{OR}=2.80,95 \% \mathrm{CI}$ 1.40-5.54) and remained statistically significant. The OR for self-reported dissatisfaction with one's sexual life among those living alone or with children was approximately three times higher than for married or cohabiting individuals $(\mathrm{OR}=2.94,95 \% \mathrm{CI} 1.44-6.01)$. The OR for reporting sexual dissatisfaction was twice $(95 \%$ CI 1.10 3.60) higher among those with other diseases than those without other diseases.
Table 3 The odds ratios (ORs) with $95 \%$ confidence intervals (95\% Cls) for self-reported dissatisfaction with one's sexual life

\begin{tabular}{lcc}
\hline Variable & Model 1* & Model 2** \\
\hline Ethnicity & & \\
Swedish-born & 1 & 1 \\
Assyrian/Syrian & 0.94 & 0.70 \\
& $(0.55-1.60)$ & $(0.40-1.25)$
\end{tabular}

Gender

Male

Female

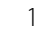

1.15
$(0.70-1.94)$

Age (years)

Age (years)

$32-59$

60-69

$\geq 70$

$\begin{array}{cc}1 & 1 \\ 1.54 & 1.52 \\ (0.83-2.85) & (0.80-2.96) \\ \mathbf{2 . 4 0} & \mathbf{2 . 8 0} \\ \mathbf{( 1 . 2 4 - 4 . 5 2 )} & (\mathbf{1 . 4 0 - 5 . 5 4 )}\end{array}$

Marital status

Married/cohabiting

Living alone/with children

2.94

$(1.44-6.01)$

$\mathrm{HbA1c}$

Normal

Abnormal

1

1.28

$(0.72-2.30)$

Medication
No
Yes

1

0.70

$(0.33-1.35)$

$\begin{array}{lc}\text { Other diseases } & \\ \text { No } & 1 \\ \text { Yes } & \mathbf{2 . 0 0} \\ & (\mathbf{1 . 1 0 - 3 . 6 0 )}\end{array}$

*Model 1 is adjusted for age and biological sex.

${ }^{*}$ Model 2 is adjusted for all explanatory variables.

\section{Discussion}

The main finding of this study is that the total prevalence of reported dissatisfaction with one's sexual life in the study population is about $50 \%$. Furthermore, there were no significant differences by ethnicity in the prevalence or ORs of reporting dissatisfaction. Instead, the factors older age, living alone or with children, and presence of other disease(s) were significantly and independently associated with the outcome variable.

Age in and of itself is a risk factor for both poorer general health [23,24] and type 2 diabetes [2]. Our 
findings regarding people aged $\geq 70$ years are consistent with the findings of other studies on negative effects of diabetes on the sexuality of elderly persons [2,24].

Although it might seem to be a self-evident topic for research, the association between marital status and satisfaction with sexual life in persons with diabetes has not been well-researched. A study exploring the relationship between marital relational domains such as intimacy and adjustment in insulin-treated adults with type 1 and type 2 diabetes concluded that the quality of marriage was associated with adaptation to diabetes [25]. Another study investigated sexual and marital satisfaction in 26 men with diabetes and 30 men with spinal cord injury who received penile prostheses or injections for the treatment of impotence. Both groups reported more disagreements with their partners about factors of importance in their relationship than a normative sample but engaged in more and more frequent sexual activity with their partners after treatment regardless of which kind of treatment they received [26].

These studies focused on satisfaction with sexual life in married persons with diabetes. Our findings indicate that persons who were living alone or with children had three time's higher odds of reporting dissatisfaction with their sexual life than those who were married or cohabiting. Further research on satisfaction with one's sexual life could therefore focus on persons with type 2 diabetes who are living alone.

Previous studies have established that individuals with diabetes who rate their health as poor often have other diseases in addition to diabetes [23,24,27]. The question of whether the primary risk factor is type 2 diabetes, complications of type 2 diabetes, or other coexisting health factors constitutes the ground for ongoing and future investigation and discussion.

In general, individuals' sexual life can be influenced by several health and sociodemographic factors. Previous studies indicate that sexual dissatisfaction, lack of desire, low sexual arousal/erection, and pain during intercourse can negatively affect the sexual life of persons with type 2 diabetes $[28,29]$. A study of 230 married Malaysian women from the general population showed that female sexual dysfunction was associated with such sociodemographic and health factors as being married more than 14 years, older age, being Malay, having less frequent sexual intercourse, having more children, having a higher academic status, and lack of lubrication [30].

Dissatisfaction with one's sexual life can be associated with physiological and psychological factors. For instance, the association between poor life satisfaction and poor general health is known to be strong. In one Swedish study [31], subjects with poor life satisfaction had a higher risk of reporting poor health $(\mathrm{OR}=15)$ than those who reported higher life satisfaction. The authors of the same study reported that country of birth, depression, and reporting many symptoms were related to poor health. Another study based on a nationally representative Swedish sample investigating life satisfaction found that having no partner and being a first-generation immigrant were associated with reporting of low levels of satisfaction [32]. We had no data on life satisfaction in the present study, but it is possible that satisfaction with one's sexual life has a strong influence on both life satisfaction and self-reported general health status.

The culture of the responders may have influenced their answers to questions about sexual life, which can be perceived as being sensitive. It is important to note that individuals with an Assyrian/Syrian ethnic background reported sexual life mostly within marriage. This is probably because of cultural and religious values; for example, in women [19,33]. The majority of Assyrian/Syrian participants in the present study stated that they accepted type 2 diabetes as something sent by God, and separation or the loss of one's partner was not followed by the choice of another sex partner. "We do not do that," said a separated 40-year-old woman when we asked if she had a sexual partner. We believe that these culturally influenced beliefs and choices may be one of the reasons why a smaller percentage of Assyrian/Syrian participants (75\%) than Swedish ones (90\%) responded to this question. Sixty-nine percent of all the nonresponding women had an Assyrian/Syrian ethnic background. It is also possible that for cultural or religious reasons, sexual life may not be an important part of some individuals' lives, which means that not having an active sexual life might be satisfactory to them.

Health-related questionnaires sometimes omit relevant questions about sexual life, often because such questions are considered private, sensitive, or even taboo for cultural or religious reasons. However, we believe that it is possible to ask such questions if they are carefully worded. Furthermore, we believe that it is important to ask such questions because sexuality is an important part of health and the quality of life. In this paper, we chose to focus on one of the three questions about sexual life in our questionnaire: "Are you satisfied with your sexual life?" (see additional file 1). This question was chosen because we regarded the inclusion of this general question as a first step in including questions on sexual life in studies on the care of persons with diabetes.

This study has several strengths. To the best of our knowledge, this is one of very few questionnaire-based health studies in Sweden to gather information about people's self-reported satisfaction with their sexual life, a factor that impacts both health and the quality of life. 
Moreover, there is noregistration by ethnicity in the official Swedish statistics, in which persons are identified by country of birth, parents' country of birth, and citizenship. Thus, a unique aspect of this study is the use of data on self-reported ethnicity. The main strength of the study is that it is based on the first cross-sectional survey of a representative sample of ethnic Assyrian/Syrian immigrants to Sweden with type 2 diabetes. Although the sample in the study is small, approximately 20,000 of the total 70,000 to 80,000 Assyrians/ Syrians in Sweden live in the town of Södertälje.

A major limitation of this study is that the sample represents Assyrian/Syrian patients with type 2 diabetes living in one town, so the results cannot be generalized to the entire population of Assyrians/Syrians with diabetes in Sweden. Another limitation is that the crosssectional nature of the study and the small sample size preclude the possibility of drawing extensive causal conclusions. An additional limitation of this study is the use of a questionnaire that was not validated. Another limitation is that the range of ages in the youngest of the three age groups (32-59 years) was much broader that the range of ages in the middle group (60-69 years). We chose to divide age in this way to obtain similar proportions of patients in each age group, which is adequate for statistical analyses. A further limitation is that we invited particular groups to participate in the study, which may have resulted in selection bias. Furthermore, in this study, we did not ask about menopause. We also lacked detailed information on "other diseases" because data on this issue was gathered via only one question, "Do you have any other diseases?" The response alternatives were "yes, which one or ones?" or "no" and we lack the answers about which other diseases the participants had. Moreover, we did not take the information on diabetes complications into account. Finally, the small number in the oldest age range in the Assyrian/ Syrian group is also a limitation.

\section{Conclusion}

No differences in self-reported dissatisfaction with one's sexual life were observed between Assyrian/Syrian and Swedish patients with type 2 diabetes. Nevertheless, the findings of this study suggest that other factors may play an important role in satisfaction with one's sexual life, including age, marital status, and the presence of other diseases in addition to diabetes.

The high prevalence of dissatisfaction with sexual life reported by responders highlights the importance of sexual life to people with type 2 diabetes, so that this factor should not be ignored in clinical evaluations. Moreover, the findings demonstrate that it is possible to include questions on sexual life in investigations of patients with type 2 diabetes as well as in other health- related, questionnaire studies, despite the sensitivity of the issue of sexuality. We found that the key to asking such questions successfully was to take into account individuals' cultural and religious identities in order to find the best way to ask questions about sensitive or even such taboo topics as sexual life.

\section{Additional material}

Additional file 1: Questions included in the present study. The file contains 8 questions that were asked as part of the original 52-item questionnaire. The answers to the 8 questions were used as the basis for the outcome and explanatory variables.

\section{Acknowledgements}

This work was supported by grants from the Research Unit in Södertälje, the Swedish Research Council (2008-3110), the Swedish Council for Working Life and Social Research (2007-1754 and 2007-1962) and the Swedish Research Council Formas (2007-1352). The authors had no conflicts of interest. The funding bodies played no role in the study design or the collection, analysis, and interpretation of data, the writing of the manuscript, or the decision to submit the manuscript for publication. We thank all the GPs and personnel at the Primary Health Care Centers who contributed to the study by gathering data. Furthermore, we thank Scientific Editor Kimberly Kane for useful comments on the text.

\section{Author details}

${ }^{1}$ Center for Primary Health Care Research, Region Skåne, Lund University, Lund, Sweden. ${ }^{2}$ Karolinska Institutet, Center for Family and Community Medicine, Stockholm, Sweden. ${ }^{3}$ Stanford Prevention Research Center, Stanford University School of Medicine, Stanford, USA.

\section{Authors' contributions}

MT planned and conducted the study and drafted the first version of the manuscript. MT and SEJ performed the statistical analysis. JT and AW contributed to the discussion section. JS read and approved the final manuscript. All authors read and approved the final manuscript.

\section{Competing interests}

The authors declare that they have no competing interests.

Received: 20 January 2010 Accepted: 8 September 2010 Published: 8 September 2010

\section{References}

1. Burke JP, Jacobson DJ, McGree ME, Nehra A, Roberts RO, Girman CJ, et al: Diabetes and sexual dysfunction: results from the Olmsted County study of urinary symptoms and health status among men. J Urol 2007, 177(4):1438-42.

2. Fatemi SS, Taghavi SM: Evaluation of sexual function in women with type 2 diabetes mellitus. Diab Vasc Dis Res 2009, 6(1):38-9.

3. Ziaei-Rad M, Vahdaninia M, Montazeri A: Sexual dysfunctions in patients with diabetes: a study from Iran. Reprod Biol Endocrino/ 8(1):50

4. Esposito K, Maiorino Ml, Bellastella G, Giugliano F, Romano M, Giugliano D: Determinants of female sexual dysfunction in type 2 diabetes. Int $J$ Impot Res 22(3):179-84.

5. Jackson G: Sexual dysfunction and diabetes. Int J Clin Pract 2004 58(4):358-62

6. Ghalayini IF, Al-Ghazo MA, Al-Azab R, Bani-Hani I, Matani YS, Barham AE et al: Erectile dysfunction in a Mediterranean country: results of an epidemiological survey of a representative sample of men. Int J Impot Res 2009.

7. Lewis RW, Fugl-Meyer KS, Bosch R, Fugl-Meyer AR, Laumann EO, Lizza E, et al: Epidemiology/risk factors of sexual dysfunction. J Sex Med 2004, 1(1):35-9. 
8. Derogatis $L R$, Burnett $A L$ : The epidemiology of sexual dysfunctions. J Sex Med 2008, 5(2):289-300.

9. Whitehouse CR: Sexuality in the older female with diabetes mellitus-a review of the literature. Urol Nurs 2009, 29(1):11-8, 29; quiz 19.

10. Walczak MK, Lokhandwala N, Hodge MB, Guay AT: Prevalence of cardiovascular risk factors in erectile dysfunction. J Gend Specif Med 2002, 5(6):19-24.

11. Archer SL, Gragasin FS, Webster L, Bochinski D, Michelakis ED: Aetiology and management of male erectile dysfunction and female sexual dysfunction in patients with cardiovascular disease. Drugs Aging 2005, 22(10):823-44.

12. Buvat J, Maggi M, Gooren L, Guay AT, Kaufman J, Morgentaler A, et al: Endocrine aspects of male sexual dysfunctions. J Sex Med 7(4 Pt 2):1627-56.

13. Ahn TY, Park JK, Lee SW, Hong JH, Park NC, Kim JJ, et al: Prevalence and risk factors for erectile dysfunction in Korean men: results of an epidemiological study. J Sex Med 2007, 4(5):1269-76.

14. Laumann EO, Waite LJ: Sexual dysfunction among older adults: prevalence and risk factors from a nationally representative U.S. probability sample of men and women 57-85 years of age. J Sex Med 2008, 5(10):2300-11.

15. Martins FG, Abdo CH: Erectile Dysfunction and Correlated Factors in Brazilian Men Aged 18-40 years. J Sex Med 2009.

16. Nicolosi A, Moreira ED Jr, Villa M, Glasser DB: A population study of the association between sexual function, sexual satisfaction and depressive symptoms in men. J Affect Disord 2004, 82(2):235-43.

17. Hjelm K, Bard K, Nyberg P, Apelqvist J: Swedish and Middle-Eastern-born women's beliefs about gestational diabetes. Midwifery 2005, 21(1):44-60.

18. Nordgren K: [Who Does History Belong To? History as Consciousness, Culture and Action in Multicultural Sweden]. Karlstad, Sweden: Karlstad University 2006.

19. Deniz F: [The maintaining and the transformation of the ethnic identity in relation to the process of the modernization: The Assyrian example]. PhD thesis Uppsala, Sweden:Uppsala university 1999.

20. Eckerbom S, Bergqvist $Y$, Jeppsson JO: Improved method for analysis of glycated haemoglobin by ion exchange chromatography. Ann Clin Biochem 1994, 31(Pt 4):355-60.

21. Hosmer D, Lemeshow S: Applied Logistic Regression. New York: John Wiley \& Sous Inc, 22002.

22. StataCorp: Stata Statistical Software: Release 9.2. College station. TX:Stata Corporation 2007.

23. McEwen LN, Kim C, Haan MN, Ghosh D, Lantz PM, Thompson TJ, et al: Are health-related quality-of-life and self-rated health associated with mortality? Insights from Translating Research Into Action for Diabetes (TRIAD). Prim Care Diabetes 2009, 3(1):37-42.

24. Unden AL, Elofsson S, Andreasson A, Hillered E, Eriksson I, Brismar K: Gender differences in self-rated health, quality of life, quality of care, and metabolic control in patients with diabetes. Gend Med 2008, 5(2):162-80.

25. Trief PM, Himes $C L$, Orendorff R, Weinstock RS: The marital relationship and psychosocial adaptation and glycemic control of individuals with diabetes. Diabetes Care 2001, 24(8):1384-9.

26. Jaworski TM, Richards JS, Lloyd LK: Retrospective review of sexual and marital satisfaction of spinal cord injury and diabetic males post penile injection or implant. Urology 1992, 40(2):127-31.

27. Madersbacher S, Temml C, Racz U, Mock K, Ponholzer A, Maier U, et al: Prevalence and risk factors for erectile dysfunction in Austria-analysis of a health screening project. Wien Klin Wochenschr 2003, 115(23):822-30.

28. De Berardis G, Franciosi M, Belfiglio M, Di Nardo B, Greenfield S, Kaplan SH, et al: Erectile dysfunction and quality of life in type 2 diabetic patients: a serious problem too often overlooked. Diabetes Care 2002, 25(2):284-91.

29. Nicolosi A, Moreira ED, Shirai M, Bin Mohd Tambi Ml, Glasser DB: Epidemiology of erectile dysfunction in four countries: cross-national study of the prevalence and correlates of erectile dysfunction. Urology 2003, 61(1):201-6.

30. Sidi H, Puteh SE, Abdullah N, Midin M: The prevalence of sexual dysfunction and potential risk factors that may impair sexual function in Malaysian women. J Sex Med 2007, 4(2):311-21.

31. Al-Windi $\mathrm{A}$ : The relations between symptoms, somatic and psychiatric conditions, life satisfaction and perceived health. A primary care based study. Health Qual Life Outcomes 2005, 3:28.
32. Fugl-Meyer AR, Melin R, Fugl-Meyer KS: Life satisfaction in 18- to 64-yearold Swedes: in relation to gender, age, partner and immigrant status. J Rehabil Med 2002, 34(5):239-46.

33. Freyne-Lindhagen M: [Identity and cultural encounter]: The Syrian women example. Lund: Studentlitteratur 1997.

\section{Pre-publication history}

The pre-publication history for this paper can be accessed here: http://www.biomedcentral.com/1471-2458/10/536/prepub

doi:10.1186/1471-2458-10-536

Cite this article as: Taloyan et al:: Ethnic differences in dissatisfaction with sexual life in patients with type 2 diabetes in a Swedish town. BMC Public Health 2010 10:536.

\section{Submit your next manuscript to BioMed Central and take full advantage of:}

- Convenient online submission

- Thorough peer review

- No space constraints or color figure charges

- Immediate publication on acceptance

- Inclusion in PubMed, CAS, Scopus and Google Scholar

- Research which is freely available for redistribution 